\title{
A antropologia forense como triagem para as análises da genética forense
}

\section{Forensic anthropology screening for analyses of forensic genetics}

\author{
Raffaela Arrabaça Francisco ${ }^{1}$, Ricardo Henrique Alves da Silva², \\ Josabeth Mendonça Pereira ${ }^{3}$, Edson Garcia Soares ${ }^{4}$, Euclides Matheucci Júnior ${ }^{5}$, \\ Edna Sadayo Miazato Iwamura ${ }^{6}$, Marco Aurelio Guimarães ${ }^{7}$
}

Francisco RA, Silva RHA, Pereira JM, Soares EG, Matheucci Júnior E, Iwamura ESM, Guimarães MA. A antropologia forense como triagem para as análises da genética forense. Saúde, Ética \& Justiça. 2013;18(1):128-33.

\begin{abstract}
RESUMO: A Genética Forense hoje é uma das principais ferramentas utilizadas em casos de identificação humana. Esta emprega as técnicas da biologia molecular para auxiliar na elucidação de crimes, principalmente na determinação da autoria deste. Contudo é sabido que a análise do DNA ainda é um exame de alto custo e que muitas vezes, em centros que não possuem um laboratório para esse fim, os mesmos têm que enviar as suas amostras para serem analisadas em outros locais, o que pode demorar meses até a obtenção do resultado. Como uma técnica aliada para a identificação humana, podemos incluir a Antropologia Forense, que vem a ser uma área de conhecimento que aplica os métodos da antropologia física e arqueologia para coleta e análise de evidências legais, buscando estabelecer a identidade de um ser humano. $\mathrm{O}$ exame antropológico forense consiste em traçar um perfil bioantropológico da vítima, incluindo: sexo, ancestralidade, idade, estatura, mão dominante (lateralidade), características dentárias, anomalias ósseas, patologias ósseas e características individuais. Com isso espera-se reduzir o número de análises de DNA forense, uma vez que a análise antropológica forense fornece dados que permite o direcionamento e a aplicação do exame de DNA para um indivíduo ou um grupo específico de pessoas. Com isto, também é possível a redução dos gastos de um laboratório de Genética Forense, pois também há a otimização dos resultados. A aplicação do protocolo para análise de ossadas do Laboratório de Antropologia Forense (LAF) serve como triagem para o exame de DNA forense. Este protocolo já é utilizado na Faculdade de Medicina de Ribeirão Preto da Universidade de São Paulo (FMRP/USP) e foi criado em 2005, em um projeto entre a University of Sheffield (UK) e o Centro de Medicina Legal (CEMEL) da Faculdade de Medicina de Ribeirão Preto da Universidade de São Paulo (FMRP/USP). Com os resultados bioantropológicos de um exame de antropologia forense é possível reduzir o número de amostras para que seja feito um exame de DNA, sendo possível reduzir o tempo e o custo de um exame dessa natureza. Isso é demonstrado na análise de caso apresentada aqui.
\end{abstract}

DESCRITORES: Genética forense; Antropologia forense; DNA.

1. Doutoranda do Centro de Medicina Legal - Departamento de Patologia e Medicina Legal da Faculdade de Medicina de Ribeirão Preto - Universidade de São Paulo.

2. Professor Doutor do Departamento de Estomatologia, Saúde Pública e Odontologia Legal da Faculdade de Odontologia de Ribeirão Preto - Universidade de São Paulo.

3. Perita Criminal do Núcleo de Perícias Médico-Legais de Ribeirão Preto.

4. Professor Doutor do Centro de Medicina Legal - Departamento de Patologia e Medicina Legal da Faculdade de Medicina de Ribeirão Preto - Universidade de São Paulo.

5. Diretor Científico. DNA Consult - Genética e Biotecnologia.

6. Professora Doutora do Departamento de Patologia da Escola Paulista de Medicina da Universidade Federal de São Paulo.

7. Professor Doutor do Centro de Medicina Legal - Departamento de Patologia e Medicina Legal da Faculdade de Medicina de Ribeirão Preto - Universidade de São Paulo.

Endereço para correspondência: Raffaela Arrabaça Francisco. Departamento de Patologia e Medicina Legal CEMEL/FMRPUSP. Rua Tenente Catão Roxo, 2418, Ribeirão Preto, São Paulo. CEP: 14051-140. E-mail: raffaela.francisco@usp.br. 


\section{INTRODUÇÃO}

A Genética Forense é o padrão ouro utilizado em casos de identificação humana em algumas situações. Esta emprega as técnicas de biologia molecular para ajudar a resolver casos criminais. A publicação de trabalhos de identificação utilizando DNA em amostras biológicas em diferentes condições, sobretudo em ossos e dentes mostra a sua importância. Também é do conhecimento de todos que a análise de DNA gera muitos custos e em muitos centros de identificação humana não há um laboratório de Genética Forense. Com isso, os exames têm que ser realizados em outros laboratórios e os resultados podem demorar meses para retornar ao centro de origem. Para resolver este problema, uma combinação de métodos científicos para a identificação humana pode auxiliar na diminuição dos custos e na rapidez da resolução dos casos. A Antropologia Forense como área cientifica, aplica métodos da Antropologia Física e da Arqueologia para coletar e analisar evidências legais para a identificação humana, sendo a solução mais viável para este problema.

\section{OBJETIVOS}

Demonstrar, através da análise de um relato de caso, como o exame antropológico forense pode ser útil na identificação humana para fins legais, reduzindo o número de análises de DNA e os custos dos exames de identificação.

\section{MÉTODOS}

Em 2005, após o desenvolvimento de um acordo de cooperação científica entre a Faculdade de Medicina de Ribeirão Preto da Universidade de São Paulo (FMRP-USP) e a University of Sheffield do Reino Unido denominado "UK - Brazil Scientific Cooperation - Forensic Anthropology and Identification of Human Remains", financiado pelo Global Opportunities Fund do Governo Britânico, ocorreu a criação do Laboratório de Antropologia Forense (LAF) no Centro de Medicina Legal (CEMEL) da FMRP-USP. Como fruto desta cooperação foi elaborado um protocolo de trabalho com ossadas humanas que atendesse às exigências internacionais, mas também se adequasse à realidade local, respondendo de modo rápido e confiável às necessidades de um exame antropológico forense. Este protocolo foi denominado de LAF/CEMEL ${ }^{1}$.

O protocolo foi criado como uma triagem para a análise de DNA e tem sido utilizado no Centro de Medicina Legal de Ribeirão Preto desde então ${ }^{2-4}$.

O protocolo LAF/CEMEL consiste na obtenção de um perfil bioantropológico forense de cada caso, contendo as seguintes características: avaliação do sexo através da pelve; avaliação do sexo pelo crânio; avaliação da ancestralidade (crânio e outros elementos); estimativa da idade em adultos (clavícula, sínfise púbica, articulação sacro-ilíaca, quarta costela e coluna vertebral); idade em jovens (fechamento de cartilagens epifisárias dos ossos); estimativa da estatura (medidas de ossos longos; estimativa da destreza manual (através da clavícula, úmero e rádio) e análise de características odontológicas ${ }^{1,5,6}$. As informações para a realização dessas análises foram obtidas de literatura especializada ${ }^{7-16}$.

O exame antropológico é realizado com a finalidade de determinar um perfil biológico e auxiliar a identificação de uma ossada. A identificação pode ocorrer utilizando-se apenas Antropologia Forense ou, em última hipótese, o perfil bioantropológico servirá como triagem com vistas a uma futura análise de DNA. Dessa forma, reduz-se o número de prováveis ossadas que possam ser de determinada pessoa desaparecida e se realizam menos análises de DNA, consequentemente, há redução de custos e, até mesmo, de tempo do processo.

\section{RESULTADO: RELATO DE CASO}

Três corpos foram carbonizados em uma explosão de um carro durante um acidente de trânsito na rodovia entre as cidades de Ribeirão Preto e Cajuru, ambas na região norte do interior do estado de São Paulo. Devido ao estado de carbonização o exame antropológico seguindo o protocolo LAF/CEMEL gerou resultados parciais, sendo necessário adaptar a análise de acordo com os restos mortais disponíveis. Era sabido que no carro havia duas mulheres e um homem com identidades conhecidas, porém irreconhecíveis entre si (Figura 1).

A análise antropológica nos permitiu identificar os restos mortais da vítima do sexo masculino presente no carro através de partes de tecidos moles ainda preservados na região pélvica.

Entre as duas vítimas do sexo feminino, havia a preservação dos arcos dentários de uma delas, o que viabilizou a execução do exame odontológico forense (Figura 2), porém a identificação da vítima através de seus arcos dentários foi prejudicada pela falta de informações ante-mortem que viabilizassem uma comparação.

Havia uma das mãos com as impressões digitais preservadas (Figura 3) que se pensava ser de uma das vítimas do sexo feminino, mas quando esta foi analisada, constatou-se que era da vítima do sexo masculino.

Apesar da extensão de destruição dos corpos por carbonização, foi possível recuperar parte da estrutura óssea da pelve, parte do útero, tuba e ovário direitos de um dos corpos enquanto do outro recuperou-se além da pelve 
óssea, um útero aumentado, com consistência endurecida em nódulos, juntamente com as tubas uterinas e ovários. Após a redução das partes moles de ambas as pelves foi possível verificar a superfície articular da sínfise púbica e da articulação sacroilíaca, o que permitiu a estimativa de idade pelos métodos de Suchey/Brooks e Lovejoy respectivamente para cada articulação ${ }^{6,12}$, conforme preconizado no protocolo LAF/CEMEL.
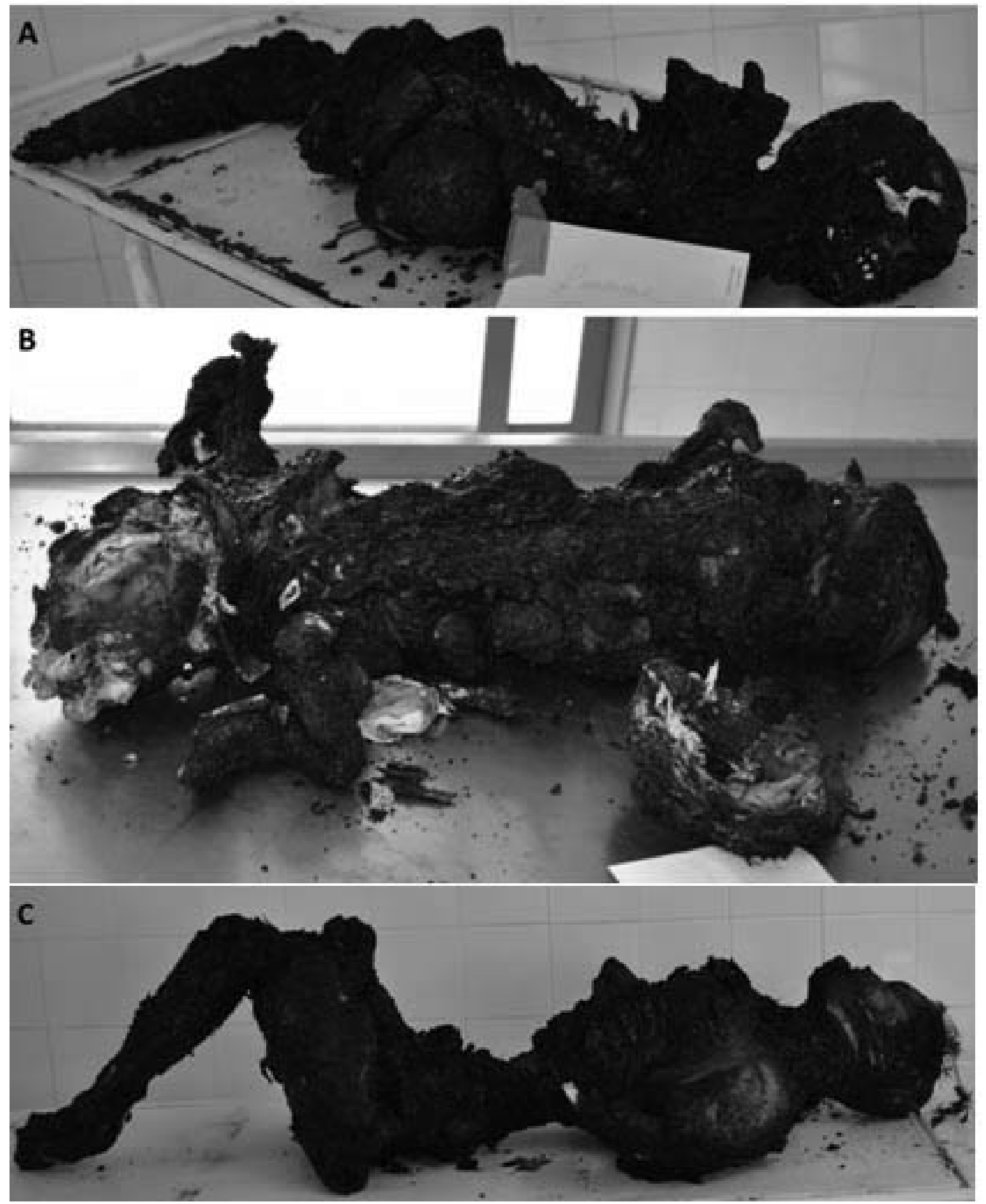

Figura 1. A- Aspecto geral dos restos mortais carbonizados da vítima referentes à "vítima feminina 01", B- Aspecto geral dos restos mortais carbonizados referentes à "vítima feminina 02", C- Aspecto geral dos restos mortais carbonizados referentes à "vítima masculina 01". Mostrando a impossibilidade de se distinguir as vítimas devido ao estado de carbonização. 


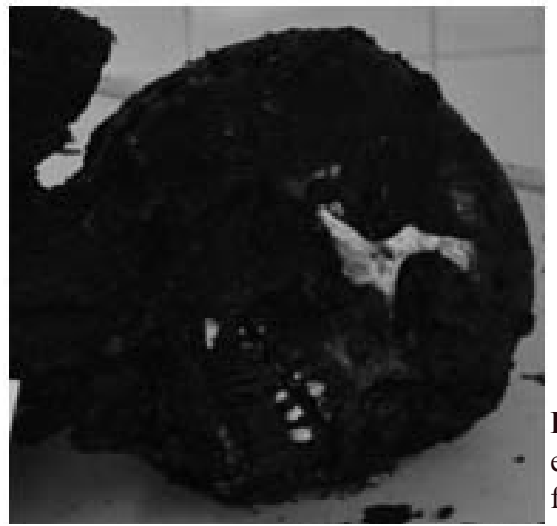

Fura 2. Aspectos odontológicos da "vítima feminina 01". Existem alguns elementos dentais preservados, mas a comparação não foi possível devido a falta de informações ante-mortem.
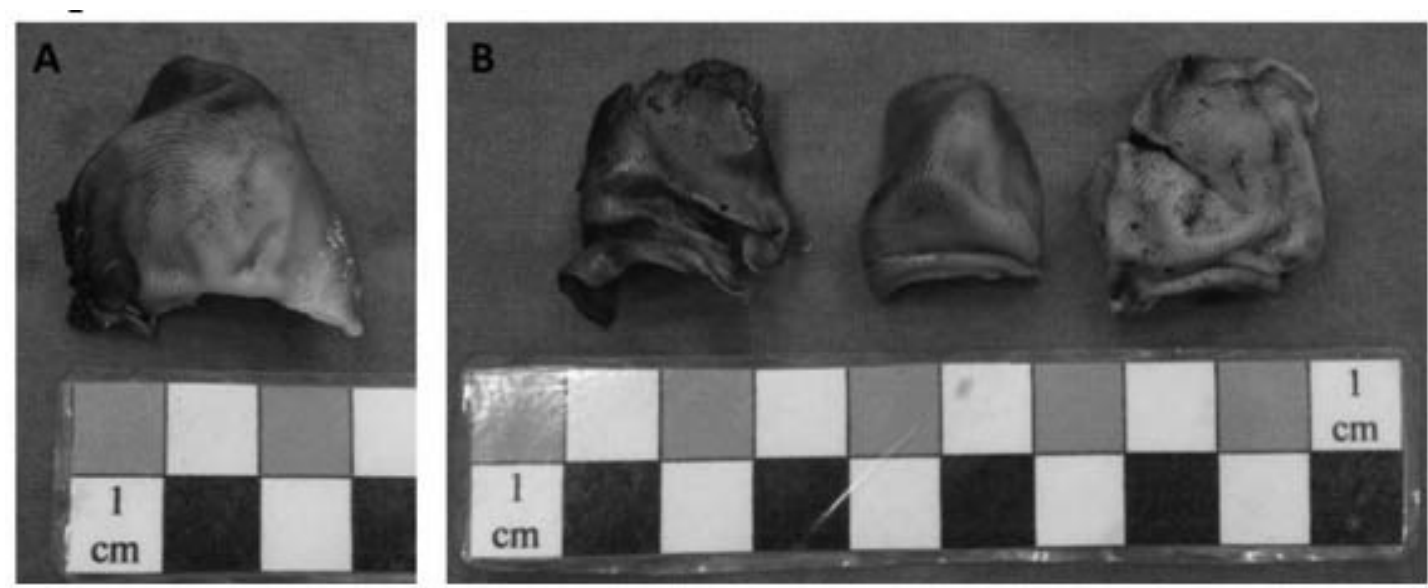

Figura 3. A- Polpa digital do polegar da mão esquerda, B- Polpa digital dos dedos indicador, médio e anular (da esquerda para a direita). Observe a preservação das cristas e sulcos papilares.
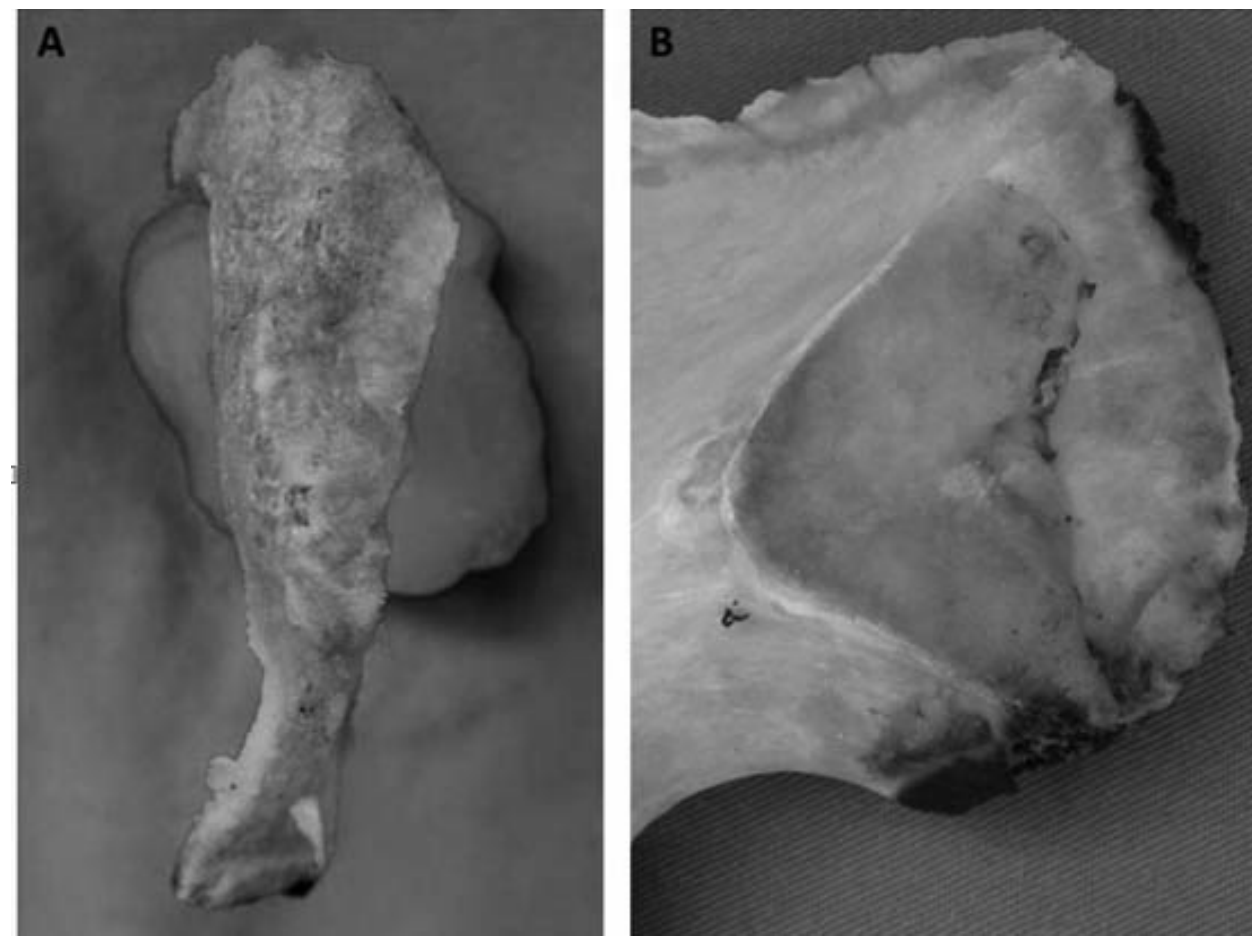

Figura 4. Ossos da pelve da "vítima feminina 01". A- Aspecto da sínfise púbica, classificado como fase 2 de acordo com Suchey / Brooks, B- Aspecto da região sacro-ilíaca classificado como estágio 3 segundo Lovejoy. 

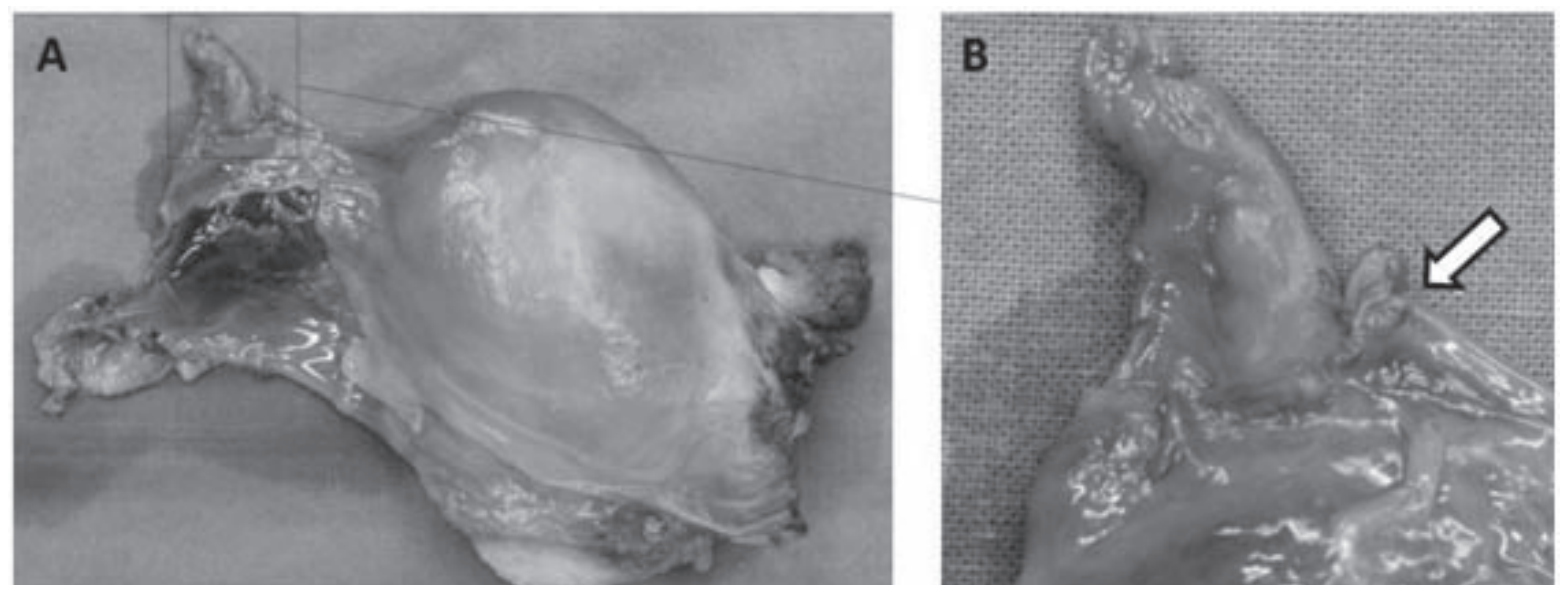

Figura 5. Órgãos reprodutores internos da "vítima feminina 01". A- Aspecto geral do útero e tubas uterinas, com destaque para a região direita do oviduto, B- Detalhe da região do oviduto direito mostrando uma sutura cirúrgica e a secção da trompa, compatível com cirurgia de laqueadura tubária.
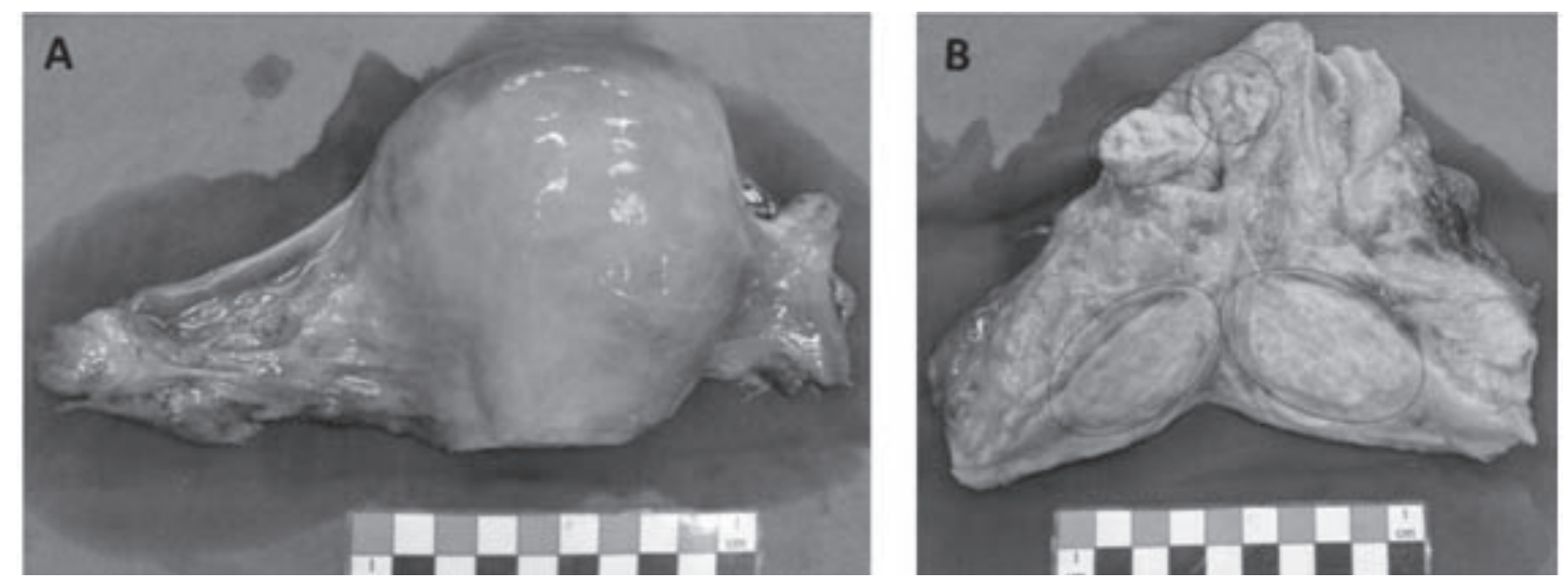

Figura 6. Órgãos reprodutores internos da "vítima feminina 01". A- Aspecto do útero, ovidutos e ovários, bem preservados mesmo após extensa carbonização do corpo, B- Visão do útero aberto mostrando a presença de miomas (círculos pontilhados).

Mesmo com a possibilidade de distinção entre as vítimas, foi solicitado o exame de DNA das vítimas do sexo feminino para garantir o controle de qualidade dos dados obtidos na resolução do caso. A análise do DNA confirmou o acerto da metodologia de antropologia no caso.

\section{DISCUSSÃO}

Os resultados da análise antropológica forense nos levaram à distinção entre os corpos das três vítimas carbonizadas. Isso demonstra que, quando a metodologia é corretamente aplicada, torna-se possível a redução do número de amostras de DNA a serem analisadas, reduzindo o tempo e os custos de uma investigação forense, trazendo também uma resposta mais rápida para a sociedade. Cada vez mais, a interdisciplinaridade torna-se necessária,tanto na pesquisa quanto na pratica forense.

\section{CONCLUSÃO}

A Antropologia Forense pode ser útil para a identificação humana como triagem para análise de DNA forense, desde que utilizada corretamente. Isso garante maior eficácia e menor custo para as análises ${ }^{4,5}$.

AGRADECIMENTOS: Aos técnicos de laboratório do Centro de Medicina Legal do Departamento de Patologia e Medicina Legal da Faculdade de Medicina de Ribeirão Preto da Universidade de São Paulo Érika Pontin Delloiagono Gual (Laboratório de Patologia Forense), José Marcelo Sechieri (Laboratório de Antropologia Forense) e Teresa Cristina Pantozzi Silveira (Laboratório de Antropologia Forense) pelo apoio na realização dos trabalhos. À Fapesp, pelo fomento à pesquisa de nossa equipe. 
Francisco RA, Silva RHA, Pereira JM, Soares EG, Matheucci Júnior E, Iwamura ESM, Guimarães MA. The forensic anthropology as screening for analyses of forensic genetics. Saúde, Ética \& Justiça. 2013;18(1):128-33.

\begin{abstract}
Nowadays, Forensic Genetics is one of the main tools used is the main tool used in cases of human identification. It uses molecular biology techniques to help in crime clarification, especially in the determination of the perpetrators. However, it is known that DNA analysis is still a high priced exam and that many times it is necessary for centers that don't have a laboratory for this purpose to send their samples to be analyzed to other places, which can take months to get the results. As an adjunct technique to human identification, we can include the Forensic Anthropology, which is a field that applies physical anthropological and archeological methods for collecting and analyzing legal evidence, in order to to establish the identification of a human being. The anthropological forensic exam consists of tracing the bio-anthropological profile of the victim, including: sex, ancestry, age, stature, handedness, dental characteristics, bone abnormalities, bone diseases and individual characteristics. Whereby, it is hoped that the number of forensic DNA analyses will be reduced, once the forensic anthropological analysis shows data that make it possible to directly apply the DNA exam to a specific person or group of people. As a result, it is also possible to reduce the costs of a Genetic Forensic laboratory because there is also optimization of results. The protocol application to the bones analyzes of the Anthropological Forensic Laboratory (LAF) serves as a screening process prior to the forensic DNA exam. This protocol is already used in the Ribeirão Preto Medical School, University of São Paulo (FMRP/USP) and it was created in 2005, in a joint project of the University of Sheffield (UK) and the Legal Medicine Center (CEMEL) of Medicine College of São Paulo University at Ribeirão Preto (FMRP/USP). With the bio-anthropological results of an anthropological forensic exam, it is possible to reduce the sample number of the DNA exam to be done, making it possible to reduce the time and the cost of these nature exams. This is demonstrated in the case report submitted here.
\end{abstract}

KEYWORDS: Forensic genetics, Forensic anthropology, DNA.

\section{REFERÊNCIAS}

1. Soares ATC, Guimarães MA. Dois anos de antropologia forense no Centro de Medicina Legal (CEMEL) da Faculdade de Medicina de Ribeirão Preto-USP. Medicina (Ribeirão Preto). 2008;41(1):7-11. Disponível em: http://www.revistas. usp.br/rmrp/article/download/676/679

2. Francisco RA, Velloso APS, Silveira TCP, Secchieri JM, Guimarães MA. Antropologia forense no Centro de Medicina Legal da FMRP/USP, estudo comparativo de casos de 1999-2009. Medicina (Ribeirão Preto). 2011;44(3):231-8. Disponível em: http://revista.fmrp.usp.br/2011/vol44n3/AO Antropologia \%20forense $\% 20$ no\%20CEMEL $\% 20 \mathrm{de} \% 20$ 1999\%20a\%202009.pdf

3. Guimarães MA, Soares-Vieira JA, Silva RHA, Evison MP. A standard procedure for accommodating forensic anthropological and genetic analysis of decomposing human remains from tropical climates. Forensic Sci Int. 2009;2(1): 165 6. DOI: http://dx.doi.org/10.1016/j.fsigss.2009.08.087

4. Evison MP, Francisco RA, Guimarães MA. Approaching utility in forensic anthropology. Forensic Sci Policy Manag. 2012:3(2):85-104. DOI: http://dx.doi.org/10.1080/19409044. 2012.744121

5. Evison MP, Francisco RA, Guimarães MA. Utility in forensic anthropology: findings contributing to case conversion. Forensic Sci Policy Manag. 2012:3(3):113-25. DOI: http:// dx.doi.org/10.1080/19409044.2012.763638

6. Brooks S, Suchey J. Skeletal age determination based on the os pubis: a comparison of the Acsádi-Nemeskéri and SucheyBrooks methods. Human Evolution. 1990:5(3):227-38. DOI: http://dx.doi.org/10.1007/BF02437238

7. Buikstra JE, Ubelaker DH, editors. Standards for data collection from human skeletal remains. Fayetteville: Arkansas Archaeological Survey Research Series 44; 1994.

8. Burns KR. Forensic anthropology training manual. Upper
Saddle River: Prentice Hall; 1999.

9. Genovés SC. Proportionality of long bones and their relation to stature among mesoamericans. Am J Phys Anthropol. 1967;26(1):67-77. DOI: http://dx.doi.org/10.1002/ ajpa.1330260109

10. Gill GW. Challenge on the frontier: discerning american indians from whites osteologically. J Forensic Sci. 1995;40(5):783-8. Disponível em: http://www.ncbi.nlm.nih. gov/pubmed/7595322

11. Isçan MY, Susan RL, Ronald KW. Age estimation from the rib by phase analysis: white males. J Forensic Sci. 1984;29(4):1094-104. Disponível em: http://www.ncbi.nlm. nih.gov/pubmed/6502109

12. Lovejoy CO, Meindl RS, Mensforth RP, Barton TJ. Multifactorial determination of skeletal age at death: a method and blind tests of its accuracy. Am J Phys Anthropol. 1985:68(1):1-14. DOI: http://dx.doi.org/10.1002/ ajpa.1330680102

13. Mckern TW, Stewart TD. Skeletal age changes in young american males - Technical report EP-45. Natick, Massachusetts: Headquarters, Quartermaster Research \& Development Command; 1957.

14. Phenice TW. A newly developed visual methods of sexing the of pubis. Am J Phys Anthropol. 1969;30(2):297-301. DOI: http://dx.doi.org/10.1002/ajpa.1330300214

15. Trotter M, Gleser GC. Corrigenda to "Estimation of stature from long limb bones of american whites and negroes," in American Journal of Physical Anthropology (1952). Am J Phys Anthropol. 1977:47(2):355-6. DOI: http://dx.doi. org/10.1002/ajpa.1330470216

16. White TD, Folkens PA. The human bone manual. San Diego: Elsevier Academic Press; 2005. 